PAPER

\title{
Fatigue and daytime sleepiness rating scales in myotonic dystrophy: a study of reliability
}

\author{
L Laberge, C Gagnon, S Jean, J Mathieu
}

See end of article for
authors' affiliations
........................
Correspondence to:
Dr L Laberge, Unité de
recherche clinique,
Complexe hospitalier de la
Sagamie, Canada, 305
rue St-Vallier, Chicoutimi,
Québec, Canada, G7H
5H6; laberluc@
saglac.qc.ca

Received 20 April 2004 In revised form

23 November 2004

Accepted 21 January 2005
J Neurol Neurosurg Psychiatry 2005;76:1403-1405. doi: 10.1136/jnnp.2004.043455

Objectives: To assess the reliability of the Epworth Sleepiness Scale (ESS), Daytime Sleepiness Scale (DSS), Chalder Fatigue Scale (CFS), and Krupp's Fatigue Severity Scale (KFSS) in patients with myotonic dystrophy type 1 (DM1).

Methods: In total, 27 patients with DM1 were administered the questionnaires on two occasions, with a 2 week interval. Internal consistency and test retest reliability were measured using intraclass correlation coefficients (ICCs), and Cronbach's $\alpha$, Cohen's $\kappa$, and Goodman-Kruskal's $\gamma$ coefficients.

Results: Internal consistency of the CFS and KFSS were adequate $(\alpha>0.70)$ but that of the ESS was weak $(\alpha=0.24)$. Both daytime sleepiness and fatigue rating scales showed significant test retest reliability. Test retest reliability for individual items revealed inconsistencies for some ESS and CFS items.

Conclusions: Reliability of the CFS, DSS, and KFSS was high, allowing their use for individual patients with DM1, but that of the ESS was lower, rendering its current usage in DM1 questionable. Fatigue rating scales such as the KFSS, which are based on the behavioural consequences of fatigue, may constitute a more accurate and comprehensive measure of fatigue severity in the DM1 population.
$M$ yotonic dystrophy type l (DMl), an autosomal dominant disorder, is the most common adult form of muscular dystrophy. DMl results from an unstable CTG repeat expansion in the $3^{\prime}$ untranslated region of the myotonin kinase gene at $19 \mathrm{q} 13.3 .^{2} \mathrm{DMl}$ is not only a muscle disease but a multisystemic disorder, including impairment of the central nervous system (CNS). ${ }^{3}$ Daytime sleepiness has been referred as the most frequent nonmuscular symptom of the disorder ${ }^{4}$ and has repeatedly been reported as one of its earliest symptoms. ${ }^{5-8}$ Available evidence suggests that daytime sleepiness is primarily the result of a CNS dysfunction. ${ }^{9}$ Fatigue is yet another prominent complaint of patients with DMl. ${ }^{3}$ A recent study reported no difference in fatigue severity between DMl patients with and without daytime sleepiness. Nevertheless, both these groups exhibited abnormal fatigue levels, ${ }^{10}$ thus advocating simultaneous use of daytime sleepiness and fatigue outcome measures in studies of patients with DMl.

In view of the deleterious impact of these latter symptoms on health and social function, ${ }^{9}$ their accurate documentation has relevant implications for the quality of life of patients with DM1. There are tests available, such as the multiple sleep latency test, ${ }^{11}$ which quantify objective daytime sleepiness, but these techniques require sophisticated equipment, and are expensive and time consuming to perform. As for fatigue, there is no such "gold standard" measuring tool; however, clinicians frequently rely on rating scales to guide treatment decisions and measure progress regarding these symptoms. Even though it is well recognised that the soundness of clinical evidence substantially depends upon the applicability of an instrument to the population of interest, ${ }^{12}$ no daytime sleepiness or fatigue rating scale has, to our knowledge, been thoroughly assessed for reliability in patients with DMl. The present study was thus conducted in order to document the reliability of the Epworth Sleepiness Scale (ESS), ${ }^{13}$ the Daytime Sleepiness Scale (DSS) specifically devised for DMl, ${ }^{14}$ the Chalder Fatigue Scale (CFS), ${ }^{15}$ and the Krupp's Fatigue Severity Scale (KFSS) ${ }^{16}$ in patients with DMI.

\section{METHODS Sample}

A list of 30 individuals was randomly selected from a registry of adult patients with classic DMl attending the Saguenay Neuromuscular Clinic (Québec, Canada), from which 27 patients with DMl (11 men, 16 women) aged 37-66 years (mean 49.6) agreed to participate in the study (participation rate $90 \%$ ). Each patient met the diagnostic criteria for definite DMl or for an obligate carrier. ${ }^{17}$ Molecular confirmation of the diagnosis was available for 24 patients $(88.9 \%)$, but a founder effect had already been demonstrated in this population. ${ }^{18}{ }^{19} \mathrm{CTG}$ repeat classes were: $<200(\mathrm{n}=3)$, 200-400 ( $\mathrm{n}=2), 401-850(\mathrm{n}=5), 851-1100(\mathrm{n}=4), 1101-$ $1500(\mathrm{n}=6)$, and $>1500(\mathrm{n}=4)$. All individuals were examined by a neurologist (JM) and had their muscular impairment categorised as mild (grades 1 and 2, no or minimal signs of muscular impairment; $\mathrm{n}=4$ ), moderate (grade 3, distal weakness; $\mathrm{n}=7$ ) or severe (grades 4 and 5 , mild to severe proximal weakness; $n=16$ ), based on our previously published muscular impairment rating scale. ${ }^{20}$ All patients completed the four questionnaires on two occasions, with a 2 week interval between them. This study was approved by the ethics committee Complexe hospitalier de la Sagamie.

\section{Measures}

Daytime sleepiness rating scales

The ESS was developed to measure the general level of sleepiness, conceptually defined as sleep propensity. It consists of eight questions asking the subject to rate their chance of falling asleep in situations commonly encountered in daily life. The unidimensional aspect of this scale has been confirmed by factor analysis. ${ }^{21}$ An evaluation in normal subjects suggests that the measure is stable over time. ${ }^{21}$

Abbreviations: CFS, Chalder Fatigue Scale; DM1, dystrophy type 1; CNS, central nervous system; DSS, Daytime Sleepiness Scale; ESS, Epworth Sleepiness Scale; KFSS, Krupp's Fatigue Severity Scale; ICC, intraclass correlation coefficient; MS, multiple sclerosis; SLE, systemic lupus erythematosus 
The DSS consists of five items derived from the Stanford University Sleep Questionnaire and Assessment of Wakefulness. ${ }^{22}$ Principal component analysis in 157 patients with DMI revealed that the DSS measured a single factor. Cronbach's $\alpha$ reliability coefficients for the five items was $0.72,{ }^{14}$ reflecting a level of internal consistency suitable for application in both research and practice. ${ }^{23}$

\section{Fatigue rating scales}

The CFS was originally used in a hospital based case-control study $^{24}$ and further refined by Chalder et al on a sample of 374 primary care patients. ${ }^{15}$ This 11 item scale measures physical and mental fatigue. The validity and reliability of the CFS has been examined in general practice attenders ${ }^{15}$ and in patients with chronic fatigue syndrome. ${ }^{25}$ Principal components analyses performed by Chalder et al..$^{15}$ supported the notion of a two factor scale for fatigue (physical and mental).

The KFSS assesses the effect of fatigue on daily activities. ${ }^{16}$ Its nine items were selected to identify common features of fatigue in both multiple sclerosis (MS) and systemic lupus erythematosus (SLE). In the initial validation study, individuals with MS and SLE were compared with healthy adults. Internal consistency of the KFSS was high for both illness groups. The KFSS demonstrated adequate concurrent validity by clearly distinguishing between patients and controls, and criterion related validity by a moderate correlation with Centre for Epidemiologic Studies Depression Scale scores in the MS, SLE, and control groups. ${ }^{16}$

\section{Statistical analysis}

Internal consistency (the degree of item interrelatedness), was assessed with Cronbach's $\alpha$ reliability coefficients from the first questionnaire completion. The test retest reliability (the estimate of the instrument's reproducibility over time assuming that no change in condition has taken place) was assessed by intraclass correlation coefficients (ICCs). ${ }^{26}$ Finally, test retest reliability for individual items (that is, the measure of association for a given item computed from both completions) was assessed with Cohen's $\kappa$ for nominal measures (for the CFS, of which scoring is bimodal) ${ }^{15}$ and with Goodman-Kruskal's $\gamma$ coefficient for ordinal measures (ESS, DSS, KFSS). Significance testing was two sided, with $\alpha$ set at 0.05 .

\section{RESULTS}

\section{Fatigue and daytime sleepiness levels}

The mean (SD) scores were 8.6 (3.5) for ESS, 5.7 (3.5) for DSS, 4.9 (2.4) for CFS, and 5.1 (1.6) for KFSS.

\section{Reliability}

Cronbach's $\alpha$ for the ESS was 0.24 , and ICC $0.68(\mathrm{p}<0.001)$. Goodman-Kruskal's $\gamma$ was significant for ESS items 1, 2, 4, 5 , and 7 (range 0.54-0.90, p<0.05). However, it was not significant for ESS item 8 (In a car, while stopped for a few minutes in traffic). In particular, all patients with DMl except one indicated that they would "never fall asleep" in this situation on the second ESS completion. In addition, Goodman-Kruskal's $\gamma$ could not be computed for ESS items 3 and 6 because all patients with DMl answered that they would "never fall asleep" on the first completion of ESS item 3 , and on both completions of ESS item 6 .

The ICC of the DSS was $0.82(\mathrm{p}<0.001)$, and GoodmanKruskal's $\gamma$ was significant for all DSS items (range 0.60$0.86, \mathrm{p}<0.05)$.

Cronbach's $\alpha$ reliability coefficient of the CFS was 0.70 , and ICC $0.81 \quad(\mathrm{p}<0.001)$. Cohen's $\gamma$ could not be computed for CFS item 11 (How is your memory?) because all patients with DMl answered either "better than usual" or "no worse than usual" on the second CFS completion. Cohen's $\kappa$ was significant for all other CFS items (range 0.40-0.76, $\mathrm{p}<0.05$ ) except item 3 (Do you feel sleepy or drowsy?).

Cronbach's $\alpha$ reliability coefficient of the KFSS was 0.86 , and ICC $0.88(\mathrm{p}<0.001)$. Goodman-Kruskal's $\gamma$ was significant for all KFSS items (range 0.55-0.88, p<0.05).

\section{DISCUSSION}

The most widely used instrument to assess daytime sleepiness is probably the ESS, but its measurement properties are questionable, particularly its reliability in clinical samples. ${ }^{927} 28$ In DMl, the ESS was used as the primary efficacy variable or as one primary outcome measure in the most recent clinical trials of modafinil for patients with daytime sleepiness. ${ }^{29}{ }^{30}$ Talbot et al observed that the ESS did not show the most significant changes with treatment, and suggested that there may be more appropriate measures of daytime sleepiness for the DM1 population. ${ }^{30}$

In contrast with previous reports that documented an acceptable internal consistency for the ESS in both controls and patients with various sleep disorders, ${ }^{21}{ }^{31}$ the present results show a weak internal consistency for the ESS in patients with DMl, indicating poor correlation between ESS items. Some insights regarding this discrepancy are provided by the test retest reliability analyses that were performed on individual ESS items. Indeed, Goodman-Kruskal's $\gamma$ coefficients could not be computed or were not significant for three of the eight "real life" situations depicted by the ESS. Particularly, patients with DMI estimated that they would "never doze" when "sitting and talking to someone", "in a car, while stopped for a few minutes in the traffic", or "sitting inactive in public place (for example, a theatre or a meeting)". The estimation of sleep propensity by patients with DMl may have been biased by the fact that severely affected patients actually experience the latter two situations infrequently, if ever. It must be noted that the dependence of the DMl population upon social welfare for their income may also restrain such activities. ${ }^{32}$ More importantly, falling asleep in such situations is uncharacteristic of patients with DMl. Indeed, it has long been established that the tendency to sleep in DMI does not occur during activity. ${ }^{6}$ It is probable that reporting no chance of dozing on some ESS items while reporting slight to high chances of dozing on other items diminished the consistency of intrasubject responses and intersubject variability, and produced low homogeneity of variances among items, consequently yielding a low Cronbach's $\alpha$. On the other hand, the present results indicate sufficient test retest reliability of the ESS in DMI, consistent with that previously observed in 87 medical students who filled the ESS twice with a 5 month interval. ${ }^{21}$

The higher test retest reliability observed for the DSS probably ensues from the fact that it was compiled from answers to questions relating to sleep and sleepiness given by patients with DMI. ${ }^{14}$ The DSS was found to correlate with the extent of muscular impairment, and its items are consistent with the clinical features most commonly noted in association with DMl related daytime sleepiness, such as daytime napping and sleepiness when attention is not being held. ${ }^{3633}$ However, its appropriateness as an evaluation instrument that measures change over time must be assessed.

The KFSS was conceived as a fatigue function measure that integrates dimensions of fatigue intensity and functional outcomes associated with fatigue, in contrast to the CFS, which measures fatigue intensity alone. ${ }^{34}$ It was accordingly suggested that the KFSS is a more effective measure of disability related fatigue in diseases that specify a state of marked functional disability. ${ }^{35}$ Hence, patients with DMl, who exhibit significant limitations in daily living activities, ${ }^{36}$ may more readily comprehend rating scales that specifically assess the effect of fatigue on daily activities, partially 
explaining the better reliability of the KFSS over the CFS. A second reason may pertain to the difference in samples used in the development of these scales. The KFSS was evaluated using patients with MS, a chronic disease for which modafinil has been shown to significantly decrease fatigue levels, ${ }^{37}{ }^{38}$ as has also been shown in DMl. ${ }^{29}$

Regarding the CFS, the poor reproducibility of CFS item 3 (Do you feel sleepy or drowsy?) may relate to our observation that patients with DMl may not present complaints of daytime sleepiness on a given day, while on a different day assert that it represents a troublesome symptom. Consequently, a more reliable clinical assessment of daytime sleepiness is likely to be provided by inquiring about the effect of daytime sleepiness on the daily activities or behaviours of patients with DMl. With regards to CFS item 11 , it is a matter of debate as to whether patients with DMl show normal ${ }^{39} 40$ or impaired memory function. ${ }^{41}{ }^{42}$ Their answers could either reflect a normal memory functioning or an incapacity to report a putative memory deficit. This latter CFS item, as well as those relating to sleepiness or apathy, may address constructs other than fatigue per se, perhaps further influencing the slightly higher reliability of the KFSS with respect to the CFS.

\section{CONCLUSION}

This first study to assess the reliability of daytime sleepiness and fatigue rating scales in DMI revealed acceptable internal consistency and reproducibility for the CFS, DSS, and KFSS, suggesting that they are suitable for application in both research and practice in this patient population. Our results, however, indicate a lesser reliability for the ESS, probably due to the poor correlation between some of its items and the habitual activities and/or clinical realities of patients with DMl, rendering its current usage in DMl questionable. In addition, other studies must determine the construct validity of daytime sleepiness and fatigue rating scales in this disease. Although daytime sleepiness and fatigue rating scales obviously provide invaluable information to clinicians and researchers, there should also be a concern about obtaining objective measurement of sleep tendency ${ }^{11}$ and exploring potential physiological correlates of fatigue. ${ }^{43}$ Given that virtually all systems may be affected in DMI, ${ }^{3}$ clarifying the mechanisms underlying daytime sleepiness and fatigue entails considering such potential aetiological factors as the cerebral, genetic, metabolic, muscular, psychological, and respiratory abnormalities that are characteristic of the disorder.

\section{Authors' affiliations}

L Laberge, Unité de recherche clinique, Complexe hospitalier de la Sagamie, Chicoutimi, Québec, Canada

L Laberge, S Jean, Département des sciences de l'éducation et de psychologie, Université du Québec à Chicoutimi, Québec, Canada C Gagnon, CIRRIS, Université Laval, Québec, Canada

C Gagnon, S Jean, J Mathieu, Clinique des maladies neuromusculaires, Carrefour de la Santé, Jonquière, Québec, Canada

J Mathieu, Centre de médecine génique communautaire, Université de Montréal, Québec, Canada

Competing interests: none declared

\section{REFERENCES}

1 The International Myotonic Dystrophy Consortium (IDMC). New nomenclature and DNA testing guidelines for myotonic dystrophy type 1 (DM1). Neurology 2000;54:1218-21.

2 Harley HG, Brook JD, Rundle SA, et al. Expansion of an unstable DNA region and phenotypic variation in myotonic dystrophy. Nature 1992;355:545-6.

3 Harper PS. Myotonic dystrophy, 3rd ed. Philadelphia: WB Saunders, 2001.

4 Hilton-Jones D. Myotonic dystrophy-forgotten aspects of an often neglected condition. Curr Opin Neurol 1997; 10:399-401.

5 Kilburn KH, Eagen JT, Heyman A. Cardiopulmonary insufficiency associated with myotonic dystrophy. Am J Med 1959;26:929-35.
6 Phemister JC, Small JM. Hypersomnia in dystrophia myotonica. J Neurol Neurosurg Psychiatry 1961;24:173-5.

7 Kohn NM, Faires JS, Rodman T. Unusual manifestations due to involvement of involuntary muscle in dystrophia myotonica. New Engl J Med 1964;271:1179-83.

8 Coccagna G, Mantovani M, Parchi C, et al. Alveolar hypoventilation and hypersomnia in myotonic dystrophy. J Neurol Neurosurg Psychiatry 1975;38:977-84

9 Harper PS, van Engelen B, Eymard B, et al. Myotonic dystrophy: present management, future therapy. New York: Oxford University Press, 2004.

10 van der Werf S, Kalkman J, Bleijenberg G, et al. The relation between daytime sleepiness, fatigue, and reduced motivation in patients with adult onset myotonic dystrophy. J Neurol Neurosurg Psychiatry 2003;74:138-9.

11 Carskadon MA, Dement WC, Mitler MM, et al. Guidelines for the multiple sleep latency test (MSLT): a standard measure of sleepiness. Sleep 1986;9:519-24.

12 Hobart J. Rating scales for neurologists. J Neurol Neurosurg Psychiatry 2003;74(suppl 4):iv22-6.

13 Johns MW. A new method for measuring daytime sleepiness: the Epworth sleepiness scale. Sleep 1991;14:540-5.

14 Laberge L, Bégin P, Montplaisir J, et al. Sleep complaints in patients with myotonic dystrophy. J Sleep Res 2004; 13:95-100.

15 Chalder T, Berelowitz G, Pawlikowska T, et al. Development of a fatigue scale. J Psychosom Res 1993;37:147-53.

16 Krupp LB, LaRocca NG, Muir-Nash J, et al. The fatigue severity scale. Application to patients with multiple sclerosis and systemic lupus erythematosus. Arch Neurol 1989;46:1121-3.

17 Griggs RC, Wood DS. Criteria for establishing the validity of genetic recombination in myotonic dystrophy. Neurology 1989;39:420-1.

18 Mathieu J, De Braekeleer M, Prevost C. Genealogical reconstruction of myotonic dystrophy in the Saguenay-Lac-Saint-Jean area (Quebec, Canada). Neurology 1990;40:839-42.

19 Heyer E, Tremblay M, Desjardins B. Seventeenth-century European origins of hereditary diseases in the Saguenay population (Quebec, Canada). Hum Biol 1997;69:209-25.

20 Mathieu J, Boivin H, Meunier D, et al. Assessment of a disease-specific impairment rating scale in myotonic dystrophy. Neurology 2001;56:336-40.

21 Johns MW. Reliability and factor analysis of the Epworth Sleepiness Scale. Sleep 1992;15:376-81

22 Miles L. Appendix I. In: Guilleminault C, eds. Sleeping and waking disorders: indications and techniques. Menlo Park, California: Addison-Wesley, 1982:384-413

23 Nunnally J, Bernstein I, eds. Psychometric theory, 3rd ed. New York: McGraw-Hill, 1994.

24 Wessely S, Powell R. Fatigue syndromes: a comparison of chronic "postviral" fatigue with neuromuscular and affective disorders. I Neurol Neurosurg Psychiatry 1989:52:940-8.

25 Morriss RK, Wearden AJ, Mullis R. Exploring the validity of the Chalder Fatigue scale in chronic fatigue syndrome. J Psychosom Res 1998;45:41 1-17.

26 Shrout PE, Fleiss JL. Intraclass correlations: Uses in assessing rater reliability. Psychol Bull 1979;86:420-8.

27 Chervin RD. Epworth sleepiness scale? Sleep Med 2003;4:175-6.

28 Miletin MS, Hanly PJ. Measurement properties of the Epworth sleepiness scale. Sleep Med 2003;4:195-9.

29 MacDonald JR, Hill JD, Tarnopolsky MA. Modafinil reduces excessive somnolence and enhances mood in patients with myotonic dystrophy. Neurology 2002;59:1876-80.

30 Talbot K, Stradling J, Crosby J, et al. Reduction in excess daytime sleepiness by modafinil in patients with myotonic dystrophy. Neuromuscul Disord 2003; 13:357-64

31 Johns MW. Sleepiness in different situations measured by the Epworth Sleepiness Scale. Sleep 1994;17:703-10.

32 Perron M, Veillette S, Mathieu J. (Myotonic dystrophy: I. Socioeconomic and residential characteristics of the patients.) Can J Neurol Sci 1989;16:109-13. French.

33 Hansotia P, Frens D. Hypersomnia associated with alveolar hypoventilation in myotonic dystrophy. Neurology 1981;31:1336-7.

34 Friedberg F, Jason LA. Understanding chronic fatigue syndrome: an empirical guide to assessment and treatment. Washington, DC: American Psychological Association, 1998.

35 Taylor RR, Jason LA, Torres A. Fatigue rating scales: an empirical comparison. Psychol Med 2000;30:849-56.

36 Mathieu J, De Braekeleer M, Prevost C, et al. Myotonic dystrophy: clinical assessment of muscular disability in an isolated population with presumed homogeneous mutation. Neurology 1992;42:203-8.

37 Rammohan KW, Rosenberg JH, Lynn DJ, et al. Efficacy and safety of modafinil (Provigil) for the treatment of fatigue in multiple sclerosis: a two centre phase 2 study. J Neurol Neurosurg Psychiatry 2002;72:179-83.

38 Zifko UA, Rupp M, Schwarz S, et al. Modafinil in treatment of fatigue in multiple sclerosis. Results of an open-label study. J Neurol 2002;249:983-7.

39 Portwood MM, Wicks JJ, Lieberman JS, et al. Intellectual and cognitive function in adults with myotonic muscular dystrophy. Arch Phys Med Rehabil 1986;67:299-303.

40 Tuikka RA, Laaksonen RK, Somer HV. Cognitive function in myotonic dystrophy: a follow-up study. Eur Neurol 1993;33:436-41.

41 Portwood MM, Wicks JJ, Lieberman JS, et al. Psychometric evaluation in myotonic muscular dystrophy. Arch Phys Med Rehabil 1984;65:533-6.

42 Rubinsztein JS, Rubinsztein DC, McKenna PJ, et al. Mild myotonic dystrophy is associated with memory impairment in the context of normal general intelligence. J Med Genet 1997;34:229-33.

43 Sharpe M, Wilks D. Fatigue. BMJ 2002;325:480-3. 